جدوى نظام الامتحانات العامة للدراسة الابتدائية

\author{
دراسة استطلاعية \\ م.د. محمد عبدالحسن ناصر \\ مركز البحوث والدراسات التربوية في وزارة التربية*
}

dr.mohammed.791@gmail.com
تاريخ الاستلام : 2021-05- تار ناريخ القبول : 04-06-2021 :

الخلاصة

تهدف هذه الدر اسة إلى التعرف على جدوى نظام الامتحانات العامة للدارسة الابتدائية، اخذين في الحسبان آراء الفاعلين الأساسين في العمل التربوي، من معلمين، ومشرفين تربويين، ومديري المدارس الابتدائية، فضلاً عن مقارنة نتائج السعي السنوي قبل الامتحانات العامة، ونتيجة الامتحانات العامة لمرحلة السادس الابتدائي.

وقد توصلت الدراسة إلى: عدم وجود اتفاق على بقاء أو إلغاء الامتحانات العامة، في آراء المعلمين، والمشرفين التربويين، ومديري المدارس، وكل فريق لديه مبرراته التي تدعم توجهه، واقترحت الدر اسة:إجر اء در اسات عن جدوى الامتحانات الوزارية في باقي المراحل الدراسية، اما ابرز التوصيات فهي

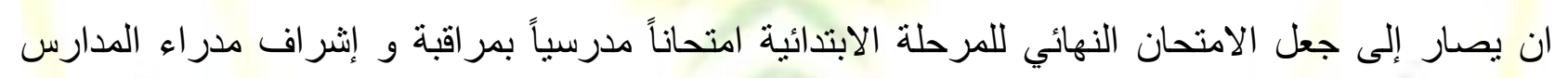
المتوسطة المغذاة من المدارس الابتدائية وملاكها. الكلمات المفتاحية:در اسة الجدوى، الامتحانات العامة، المدارس الابتدائية 
Feasibility of the general examination system for primary study

\section{An exploratory study}

M.d. Mohammed Abdulhasan Naser

Center of Research and Educational Studies/ Ministry of Education

Receipt date: 2021-05-28

Date of acceptance: 2021-06-04

\section{Abstract}

Our current study examines the feasibility of continuing the general examinations system for primary school in particular, taking into account the opinions of the principal actors in the educational work, including teachers, educational supervisors, and primary school administrators, as well as comparing the results of the annual pursuit before the general examinations, and the results of the public examinations for the sixth stage Primary.

The study concluded: There is no agreement to maintain or cancel the general examinations regarding the opinions of teachers, educational supervisors, and school directors, and each team has its own justifications that support its orientation. It is to make the final examination for the primary stage a school examination under the supervision and supervision of the principals of middle schools fed by primary schools and their owners.

Key words: feasibility study, general examinations, primary schools 
يعد النظام التعليمي في العراق من اعرق وأقدم الأنظمة التعليمية والتربوية في المنطقة، وقد حقق انجازات مهمة في المجال التربوي، غير ان الملاحظ على هذا النظام اعتماده على آليات تكاد ان تكون ثابتة من بداية تأسيس وزارة المعارف العراقية(وزارة التربية اليوم) ، وهو نظام الامتحانات العامة، وقد أشارت العديد من الدراسات والبحوث المحلية والدولية إلى جملة من السلبيات التي تشوب هذا النظام وصولاً إلى التصريح بعدم جدواه، بل وضرره على المخرجات التربوية، غير ان هذه الدعوات ومن عقود لم تتال العناية أو الاهتمام المفضي إلى تغيير أو تطوير هذا النوع من الاختبارات . ان الاطلاع على حقيقة الامتحانات العامة في العراق ( البكلوريا) يعد أمر في غاية الأهمية لان وزارة التربية استخدت هذا النوع من الاختبارات من عقود لمنح شهادة تخرج وكمعيار لقبول التلامذة في المرحلة المتوسطة بالمدارس العادية أو مدارس المتميزين والمتفوقين في العقود المتأخرة.

ويعود اسم امتحان البكلوريا إلى منظمة دولية تسمى (المنظمة الدولية للبكالوريا) والتي تأسست في عام 1968،وهذه المنظمة يوفر برنامجها تعليم متكامل عالي المستوى تثترك فيها عناصر متعددة كالمناهج الرصينة والمحتوى المتكامل وطرق التدريس الحديثة والفعالة،لحل المشكلات والعمل الجماعي والاستكشاف. اما من حيث الامتحانات، فيخضع التلامذة والطلبة إلى امتحانات (البكلوريا) العامة التي تقيس المهارات المعرفية العليا للطلبة ومدى قدرتهم على فهم وتحليل وتطبيق محتوى مواد دراسية تتضمن معلومات متعددة ومتتوعة ، فضلاً عن إخضاع التلامذة والطلبة للامتحان الذي يكون وفقاً لنظرية المعرفة عبر أسئلة عديدة تتمحر حول ( كيفية معرفة التلامذة والطلبة أنهم يعرفون) ، فضلاً عن ذلك تقويم التلامذة والطلبة في مجالات الإبداع. وعلى ما يبدو أن الامتحانات العامة في العراق ليس لها علاقة بامتحان البكلوريا، التي تمثل اختبارات تحصيلية تقيس المستويات المعرفية الدنيا ممثلة بالحفظ والاكتساب والتذكر من دون المهارات الأخرى. ان هذا النوع من الامتحانات العامة غير الفعالة التي تستخدها وزارة التربية لتحديد مستقبل التلامذة والطلبة لا تُعتمد في كثير من الدول بوصفها المعيار في تحديد قبول التلامذة والطلبة سواء في مراحل دراسية أعلى أو في الجامعات والكليات، بل تستخدم كمعيار في عدة مجالات منها: كثهادة تخرج من المرحلة الإعدادية (دبلوم)، تحديد مستوى الأداء للمدارس، تحديد نقاط القوة والضعف في المناهج الدراسية ، تحديد جودة التعليم، استخدام بياناتها في مكافأة المديرين والمعلمين المتفوقين، وكذلك مطابقة الأهداف التعليمية مع النتائج المتحققة (التقويم). علماً ان هذا النظام ( الامتحان الوزاري) يعمل به فقط في العراق وسوريا ولبنان وحسب علم الباحث فقد الُغي في لبنان. لاللك نجد انتا بحاجة ماسة إلى حزمة من التغييرات بالامتحانات العامة في العراق، وعلى رأسها تغيير الامتحان الحالي البكلوريا) ولاسيما في المرحلة الابتدائية، لوجود جملة من التحديات والصعوبات والمعوقات ذات الأثر السلبي على التلامذة، 
1.

2. ضعف الوسائل التعليمية من مختبرات ووسائل إيضاح وأجهزة الكترونية مخصصة للعملية التعليمية. 3. ضعف قدرات الملاك التدريسي وانعدام الحوافز التعليمية.

4. ضيق الصفوف الدراسية بالدارسين من مختلف المراحل مما يثقل كاهل التلميذ والمعلم في التركيز والاستفادة القصوى

من الحصة الدراسية.

$$
\text { 5. التغيير المستمر وانعدام الاستقرار في الملاكات التربوية للعام الدراسي.. }
$$

وهنالك عوامل أخرى خاصة بالتلميذ وبيئة المحيطة به، وبالتالي فإننا بحاجة إلى إعادة النظر الجاد بمجمل العملية التربوية وبجميع مراحلها وعناصرها ومبادئها وفلسفتها وأهدافها،لأجل تطويرها ومواكبتها لما يجري في العالم، لتعزيز نقاط القوة، والحد من

$$
\text { الثانياً/ أهداف الدراسة: } 1 \text { المتباتة. }
$$

2. التعرف على الرؤى البديلة عن الامتحان العام الوزاري (البكلوريا) التي تضمن تحقيق الأهداف التربوية المتوخاة من

$$
\text { الامتحان. }
$$

3. تعرف توجهات أعضاء الهيئة التربوية في المرحلة الابتدائية الامتحان العام الوزاري (البكلوريا) 4. عرض المبررات الذاتية والموضوعية لبقاء أو إلغاء الامتحان العام الوزاري (البكلوريا) للمرحلة الابتدائية.

ثالثاً / أهمية الدراسة:

1. ان دراسات الجدوى المختلفة تمثل الأساس العلمي لتقييم اي نظام أو قرار، قبولاً أو رفضاً، وان إخضاع نظام الامتحانات العامة للتقييم حالة ايجابية تسهم في معرفة ايجابيات وسلبيات هذا النظام، وإمكانية استبداله أو تعديله

$$
\text { وتطويره لتحقيق الأهداف العملية التربوية. }
$$

2. ان الأسلوب المتبع في تقييم التلامذة والمتمثل بالامتحانات العامة يتسم بعدم الوضوح في الأهداف وعدم الدقة في صياغة مبادئ التقييم .... 3. عرضت تصورات ورؤى عينة من أعضاء الهيئة التربوية بشأن نظام الامتحانات العامة، مكونة من مديري الإدارة للمدارس الابتدائية والمعلمين والمشرفين التربويين. 1. 1 الحدود المكانية: المديريات العامة للتربية الست في بغداد. 2. الحدود البشرية: مديرو المدارس الابتدائية، ومعلمو المرحلة الابتدائي والمشرفون التربويون. 3. الحدود الزمانية: العام الدراسي 2018-2019. 
المفاهيم والمصطلحات العلمية:

أولاً/ دراسة الجدوى:

عرفت دراسة الجدوى على إنها أداة علمية تستخدم لترشيد القرارات الجديدة أو تقييم قرارات سبق اتخاذها، أو القيام بمفاضلة بين البدائل المتاحة وذلك على أسس فنية، وعلمية، ومالية، وعلى وفق معطيات محددة.(زردق، 2011، ص232). كما تعرف دراسة الجدوى بأنها: سلسلة من الدراسات التي تقوم على افتراضات معينة وأهداف محددة تؤدي إلى اتخاذ الموقف النهائي بقبول المشروع أو برفضه وذلك اعتماداً على مجموعة من المعايير، بغية التعرف على قدرة المشروع في بلوغ أهدافه المنشئ من اجلها. (زردق، 2011، ص33) ويعرف حوري (حوري، 2007، ص12) دراسة الجدوى: على إنها مجموعة من الأساليب والأدوات والاختبارات والأسس العلمية التي تعمل على المعرفة الدقيقة لاحتمالات نجاح أو فثل مشروع معين، واختبار مدى قدرة هذا المشروع على تحقيق أهداف محددة تتمحور حول الوصول إلى اعلي عائد ومنفعة. ويمكن ان نستتتج مما سبق ان دراسة الجدوى تتصف بأنها: • • • طريقة عملية تبتعد عن العشوائية في اتخاذ القرارات. • تستتد على أسس وركائز تستوجب دراسات وافية. أما تعريفنا الإجرائي لدراسة الجدوى: النتائج التي تسفر عنها الدارسة الحالية في قبول أو رفض أو اقتراح بديل للامتحانات العامة لمرحلة السادس الابتدائي. ثانياً/الامتحانات العامة: يعرف القاموس التربوي الامتحانات بأنها تقنية مستخدمة لتقييم قدرة أو انجاز أو أداء قائم في موضوع ما (فريق من الخبراء، (75، 2007 اما تعريف وزارة التربية العراقية للامتحانات الوزارية (البكلوريا) فهو: محكات مباشرة تعدها لجان متخصصة في وزارة التربية، جمهورية العراق لقياس مستوى تحصيل التلميذ أو الطالب في المرحلة النهائية، وتعد معياراً لمنح الثهادة.(نظام الامتحانات العامة،رقم (19)لاسنة 1972). وعلى وفق السابق من التعريفات فان الامتحان هو وسيلة للتأكيد من كفاية معلومات الفرد ومقدار المهارات التي يمتلكها، عبر الإجابة على مجموعة من الأسئلة أو القيام بعمل ما أو حل مشكلة معينة.

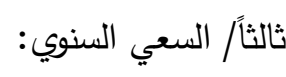

تتص المادة (62) ان معدل درجات التلاميذ في النصف الأول والنصف الثاني من السنة الدراسية وامتحانات نصف السنة، تمثل درجة السعي السنوي، وتتألف الدرجة النهائية لهم من معدل درجة السعي السنوي ودرجة الامتحانات النهائية بدوريها الأول أو

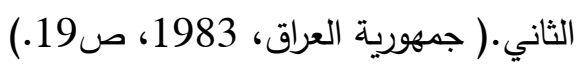


يعرف الإشراف على انه كل النشاطات التي تختص مباشرة وبصور أساسية بدراسة وتحسين الثروط المتصلة بعملية التعليم والتعلم.( متولى، 1983، ص19) . والإشراف مهمته تكمن في تعليم المعلمين كيفية التعليم والقيادة المهنية وإعادة تثكيل التربية العامة.( العاجز، 2009، ص14). وبذلك تكون مهمة الإشراف التربوي مهمة قيادية تمد الجسور بين الإدارة والمنهج والتدري. خامساً/ المعلم :

تحدد المادة (23) من الفصل السادس( الهيئات التعليمية) المعلم بناءً على مجموعة من الاشتراطات وهي ( يشترط فيمن يعين معلماً في المدارس الابتدائية ان يحمل مؤهلاً تربويا لا يقل عن الثهادة الجامعية الأولية أو يحمل مؤهلاً تربوياً لا تقل مدت دراسته عن 2 سنتين بعد الدراسة الإعدادية أو (5) خمس سنوات بعد الدراسة المتوسطة). (الوقائع العراقية، 2011، ص9. المبحث الثالث: دراسات سابقة: الدراسة الأولى: دراسة هناء رجب، التعليم في العراق بين الماضي والحاضر، مجلة المعلم الجديد، تتاولت الدراسة التعليم في

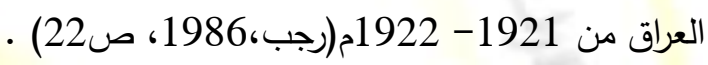
تثير الدارسة إلى ان أول الامتحانات العامة للدراسة الابتدائية أجريت عام 1921-1922 وشملت (150) تلميذاً وتلميذة ، نجح منهم (40) تلميذاً وتلميذة كانت نسبة النجاح (26,6\%). وهذا يعني ان (73,4\%) لم ينجح في هذا الامتحان، الأمر الذي ترتب عليه هدر مادي ومعنوي كبير ، وضياع لفرص الإفادة من الطاقات والجهود في تلك المرحلة.

الدراسة الثانية: دراسة منرو بول، المعروفة بتقرير لجنة الكثف والتهذيب في عام 1932م(بول، 1932،ص 67-69 ) شخصت هذه الدراسة استمرار نسب الرسوب في وتيرتها المرتفعة، الأمر الذي جعل لجنة الكثف والتهذيب تئكد على ان سبب هذه النسب العالية من الرسوب يعود في اغلبه إلى نظام الامتحانات الموحد في المملكة والذي تديره وزارة المعارف، لان كل جهود المدرسين والتلادذة والطلبة تتركز في الاستعداد لهذا الامتحان والنجاح فيه، الأمر الذي يؤدي إلى إهمال الجوانب التربوية الأخرى.

الدراسة الثالثة: مقررات وتوصيات المؤتمر الأول للتربية والتعليم وزارة المعارف 1960م (وزارة المعارف، 1960، صانه1-83) شخصت لجنة المؤتمر الأول للتربية والتعليم في وزارة المعارف وجود ضعف وخلل في مجال الامتحانات ولذلك وضعت جملة من التوصيات من أهمها: أ- النظر في وضع اختبارات نفسية للقدرات الفكرية العامة والخاصة. ب- - ضرورة وضع خطة واسعة ومنظمة ترمي إلى إصلاح الامتحانات من حيث وظائفها وأساليبها ومحتواها. 
الدراسة الرابعة:دراسة اللجنة المشتركة من الوفد الثقافي للجمهورية العربية المتحدة وممثلي التربية والتعليم بالجمهورية العراقية

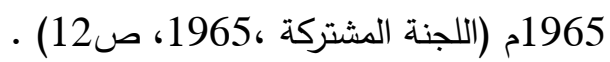

تمكنت اللجنة العلمية العربية المشتركة عن التعليم في العراق من الوصول إلى مجموعة من التصورات عن العملية التربوية ومعوقاتها وابرز المشاكل التي تحيط بها، وخلصت إلى ضرورة ان تتجه أسئلة الامتحانات إلى قياس قدرة الطالب على التصرف والتعليل والتتكير ، والى قياس الجوانب العملية منها ، وألا تقتصر الأسئلة على مجرد اختبار الحفظ والاستظهار .

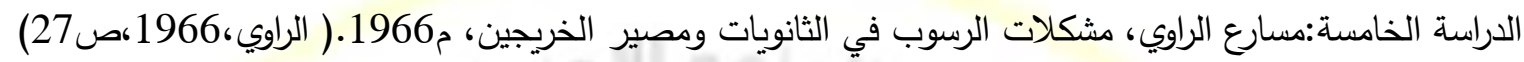
لقد توصل الباحث في هذه الدراسة إلى نتيجة وخلاصة مركزية وهي ان من بين أهم أسباب ارتفاع نسب الرسوب هو(إتباع الأساليب التقليدية في الامتحانات المدرسية من حيث وضع الأسئلة وتصحيح الدفاتر الإمتحانانية وإعلان النتائج وعدم محاولة

\section{تطويرها.}

من هنا فإننا نرى ان أغلب الدراسات والبحوث التربوية أكدت ومن وقت مبكر على الجوانب السلبية للامتحانات العامة، التي مازالت مستمرة حتى يومنا هذا بذات الكيفية والماهية. وعلى ما يبدو ان النظام ألامتحاني الذي يعده البناء التربوي العراقي من بين المرتكزات الأساسية بقي على ذات النمط والأسلوب وآليات العمل حتى يومنا هذا، وطوال العقود المتقادمة لم يحدث تغيير حقيقي أو جذري في هذا النظام ألتقلدي والقديم، والذي يخالف و يختلف عمّا تعتمده النظم التربوية الحديثة، فكان الامتحان ولازال يعني للطلاب الخوف، والقلق، والتوتر، لأنّ الأجواء المدرسية، والأسريّة، تُشعره بأنّها اللحظات الحاسمة، التي يتوقف عليها النجاح، أو الفشل، لهذا فان التلامذة والطلبة يعيشون فترة الاختبار ، وهم في أصعب حالاتهم النفسيّة. أمّا النظم التربوية الحديثة فقد غيرت مفاهيمها في هذا الصدد لتواكب التطوّر الحضاري، والتقدّم العلمي، والتقني القائم على تحقيق نواتج تعليمية ناجحة، حتى أصبح الامتحان يُعرّف بأنّه قياس وتقويم جميع الأعمال التي يقوم بها المعلم، من أجل الحكم على مستوى تحصيل التلامذة والطلبة ومدى استيعابهم لمّا يتلقونه، من المنهج الدراسي،وأساليب التدريس المتّبعة. هذه التطورات تفرض على الجهات ذات العلاقة العمل الجاد من اجل إيجاد البدائل لهذا النظام أو تطويره بالقدر الذي يتجاوز فيه السلبيات والمعوقات التي تكتنفه. 


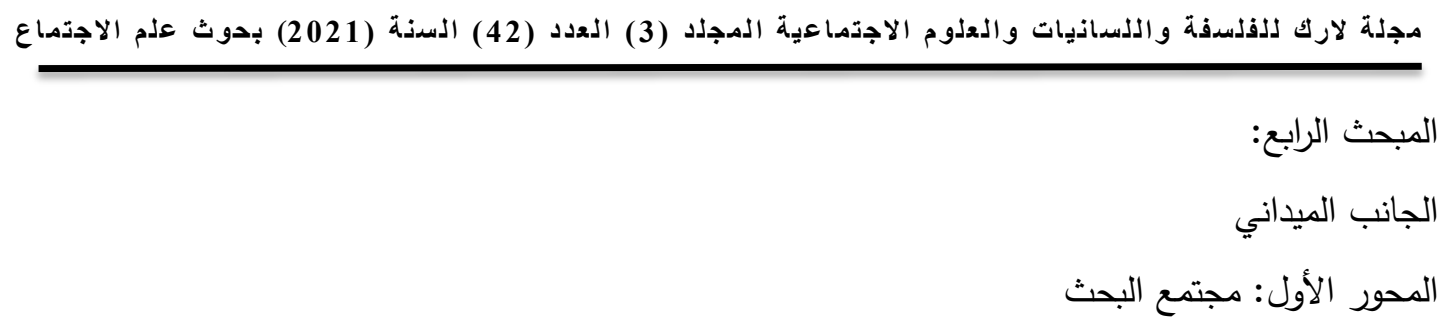

يتكون مجتمع البحث الحالي من المعلمين، ومديري المدارس، والمشرفين التربويين، في المديريات العامة الست للتربية في بغداد. اما عينة البحث فقد تكونت من المعلمين بنسبة (0,5\%) لكبر حجم هذه الشريحة، و (10\%) من مديري المدارس، و(10\%) من المشرفين التربويين. وكما موضحة في الجدول (1). جدول (1) يبين مجتمع البحث/ وعينة البحث ممثلة بالنسبة المئوية للمعلمين، ومديري المدارس، والمشرفين التربويين.(وزارة التربية،2018-2019، جدول (21- 21)

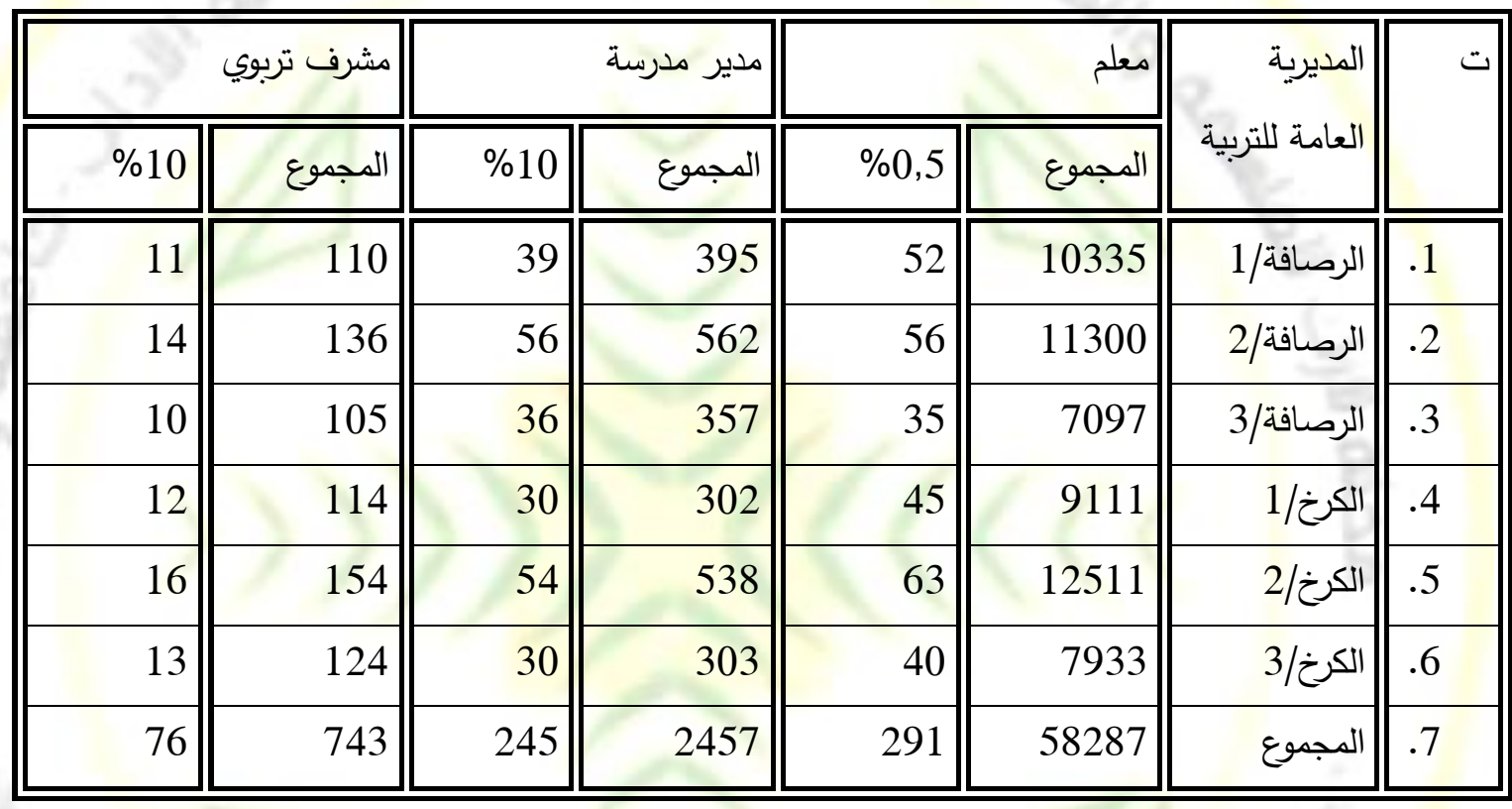

إجراءات الدراسة :

من اجل تحقيق أهداف الدراسة اعتمد الباحث نوعين من الإجراءات وهي: • المحور الأول/ دراسة استطلاعية :

من اجل الوصول إلى نتائج دقيقة تخدم موضوع الدراسة الحالية عمد الباحث إلى إجراء دراسة استطلاعية لأصحاب الميدان ( المعلم ، المدير ، المشرف التربوي) للدراسة الابتدائية عبر توجيه سؤال مفتوح لعينة الدراسة والبالغة ( 291) معلم ابتدائي، موزعين على المديريات العامة للتربية، و (245) مدير مدرسة ابتدائية، يمثلون المديريات العامة للتربية الست، و (76) مشرفاً تربوياً، موزعين على المديريات العامة الست للتربية. والسؤال هو: هل أنت مع استمرار نظام الامتحانات العامة الوزارية البكلوريا لمرحلة السادس الابتدائي؟ أم لا؟ إذا كان الجواب (نعم) أم (لا) اذكر أسباب ذلك؟ 
اولاً: الجدول (2) يبين إجابات المبحوثين من المعلمين على نص السؤال الذي ينص هل أنت مع استمرار الامتحانات العامة الوزارية البكلوريا لمرحلة السادس الابتدائي؟

\begin{tabular}{|c|c|c|c|}
\hline$\% \vee$ & 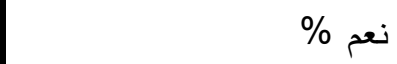 & المعلم & ت \\
\hline 34 & 66 & الرصافة 1 & .8 \\
\hline 26 & 74 & الرصافة2 & .9 \\
\hline 31 & \begin{tabular}{|l} 
\\
\end{tabular} & الرصافة3 & .10 \\
\hline 29 & 71 & الكرخ1 & .11 \\
\hline 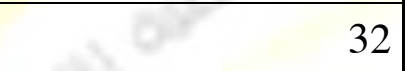 & 68 & +2 & .12 \\
\hline 30 & 70 & الكرخ3 & .13 \\
\hline
\end{tabular}

وفي الجدول أعلاه يتضح ان إجابات المعلين على بقاء الامتحان الوزاري البكلوريا كانت بالثكل الآتي: أعلى نسبة إجابات بـ(نعم) لبقاء نظام الامتحانات العامة البكلوريا للرصافة/2 بواقع 74\%، و (لا) بنسبة 26\%، تأتي بعدها الكرخ/1، بنسبة إجابات بـ(نعم) بلغت 71\%، و (لا) بنسبة 29\%، ومن ثم الكرخ/3 بنسبة إجابات بـ(نعم) 70\%، و (لا) بنسبة 30\%، تليها الرصافة/3 بنسبة نعم لبقاء الامتحانات العامة بلغت 69\%، و (لا) بنسبة 31\%، بعدها الكرخ/2 بنسبة نعم بلغت 68\% و (لا) 32\%؛ واخيراً الرصافة/1 بنسبة إجابات بـ(نعم) 66\% و (لا) 34\%، مما يعني ان نسبة إجابات المعلمين بـ(نعم) لصالح بقاء النظام الحالي قد بلغت 69,6\%. اما أسباب إجابات المبحوثين بـ (نعم) لصالح بقاء النظام ألامتحاني الحالي، أو (لا)بالضد من بقائه فكان كالآتي: أ- أسباب الإجابة المعلمين بـ( نعم) لبقاء النظام الامتحان الحالي البكلوريا للأسباب الآتية: 1. تعريف وتعويد التلميذ على الامتحانات الوزارية لأنه سيخوض هذه التجربة في المراحل القادمة.

2. 1 الامتحان يكون بمثابة نهاية فاصلة للمرحلة الابتدائية. 3. من أجل ان يكون المعلم مجبر على إكمال المادة الدراسية. 4. الامتحان الوزاري منصف للتميذ. 5. إعطاء التقدير الصحيح لمستوى التلامذة. 6. بيان كفاءة المعلمين على مدار العام الدراسي. 7. تشجيع التلاميذ على الإجابة والامتحان في غير مدارسهم ومن غير معلميهم (التكيف مع بيئته الجديدة). 8. إلغاء الامتحان العام يسهم في تراجع المستوى العلمي للتلامذة. 9. زيادة الرصانة العلمية للشهادة الابتدائية في العراق. 10ـ الحد من المحسوبية والذاتية بنجاح التلاميذ. 
11.تحفيز التلاميذ على الدراسة.

12. التزام الإدارات بنسب نجاح معينة.

13.حث المعلمين على تحسين أدائهج بهدف حصولهج على نسب نجاح عالية.

14.صعوبة إجراءات امتحانات نزيهة في المدارس لأسباب عدة أبرزها تضارب المصالح.

15. عدم وجود آليات مقترحة بديلة.

16. التحيز لصالح بعض التلاميذ.

17. الامتحانات العامة من أهم الوسائل في تقييم التلاميذ.

18.الامتحانات العامة تسهم في رصانة الأسئلة.

19.نمطية الأسئلة والأجوبة في الامتحانات العامة تُغاير نمطها في الأسئلة الثهرية.

20. اعتماد التلميذ على ذاته لحصول على درجة النجاح.

21. يعطي التلميذ الثجاعة لمواجهة الاختبار وتتمية القدرات.

22. الأسئلة موضوعية بعيدة عن الروتينية.

ب- أما إجابات المعلمين بـ(لا) لبقاء الامتحان العام البكلوريا وبنسبة 30,4\%فقد كانت مبرراتهم هي:

1. ان اغلب دول الجوار لا يوجد فيها نظام الامتحان الوزاري للسادس الابتدائي.

2. بسبب حالات الغش من قبل المراقبين وبالاتفاق مع إدارات المدارس.

3. نظام قديم ولا يواكب التطور الحاصل لأنظمة الامتحانات.

4. بوجود السعي السنوي ليس هناك مبرر للامتحانات العامة البكلوريا.

5. تقدير مستوى التلميذ ودرجته من قبل المدرسة ومعلميهم لأنهم اعرف بذلك.

ثانياً: الجدول (3) يبين إجابات المبحوثين من مديري المدارس الابتدائية على بقاء الامتحانات العامة الوزارية البكلوريا لمرحلة

السادس الابتدائي من عدمها؟

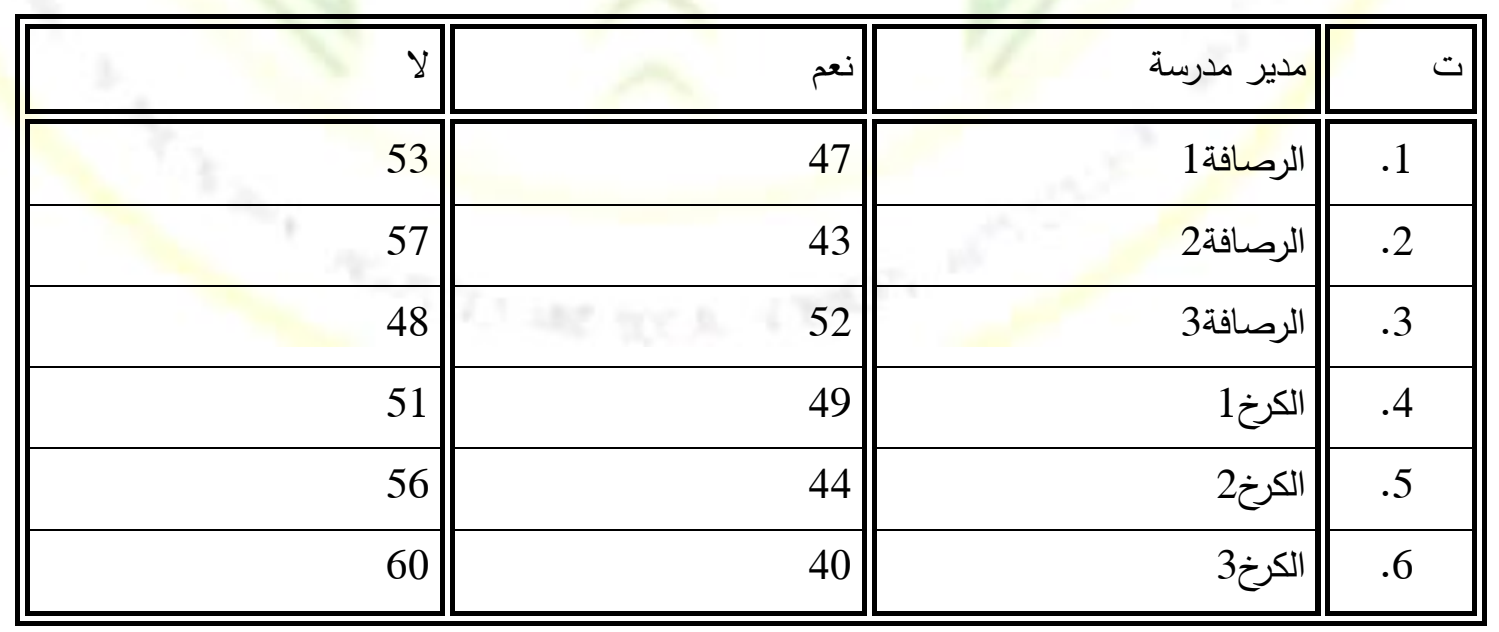


يتضح من الجدول أعلاه أن نسبة مديري المدارس الذين أجابوا بـ(نعم) كانت تقارب 46\% لصالح بقاء نظام الامتحان الحالي، في حين ان قرابة 54\% كانت إجاباتهم غير مؤيد لبقاء النظام الحالي للامتحانات وقد توزعت إجاباتهم بالثكل الآتي: أعلى نسبة إجابات كانت لمديري مدارس الرصافة/3 بـ(نعم) لصالح بقاء الامتحانات العامة البكلوريا بنسبة 52\% مقابل الإجابة بـ(لا) لبقاء نظام الامتحانات بنسبة48\%، تليها الكرخ/1 بأجابة 49\% من المديرين بـ (نعم)، و ( لا) بنسبة 51\%، وبالمرتبة الثالثة الرصافة1 بالإجابة بـ(نعم) 47\% و(لا) بنسبة 53\%، الكرخ/2نسبة الإجابة بـ(نعم) 44\%، ونسبة الإجابة (لا) 56\%، في حين جاءت إجابات مديري الرصافة/2 بنسبة الإجابات ب(نعم) 43\%، والإجابة بـ(لا) 57\%. واخيراً إجابات مديري

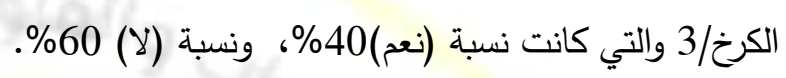

وقد كانت أسباب الإجابة ب(نعم) و (لا) من مديري المدارس بالثكل الآتي: أ- أسباب الإجابة بنعم لبقاء النظام ألامتحاني الحالي وهي:

ان مبررات مديرو المدارس الذين كانت إجاباتهم بـ(نعم) لصالح بقاء نظام الامتحان الحالي البكلوريا، فهو يعود للأسباب آلاتية: 1. الامتحانات العامة منصفة للتلامذة.

2. من أجل أن يعتاد التلامذة أجواء الامتحانات الوزارية. 3. تجربة الامتحان العامة تجربة أولية، تؤهله لباقي المراحل الدراسية. 4. إنها تلزم التلميذ والمعلم على إكمال المنهج الدراسي كاملاً. 5. الابتعاد عن الذاتية في وضع الدرجات للتنامذة. 6. أسئلة الامتحان الوزاري تكون شاملة وتراعي المستويات كافة. 7. تجعل المعلم ملم بمادته الدراسية لأنها تدخل ضمن تقيمه السنوي. 8. هو اختبار لقدرات التلميذ الدراسية الحقيقية. 9. لتأهيل التلامذة بحسب المستوى العلمي بعيداً عن المحسوبية والمنسوبية. 10. أكثر عدالة بين التلامذة وبين مستوياتهم الحقيقية. 11 1. الحصول على نتائج عادلة وتخلق روح المنافسة بين إدارات المدارس. 12.تعد معيار للمعلم والتلميذ والإدارة. ب- - اما من أجاب من مديري المدارس ب (لا) للنظام ألامتحاني العام البكلوريا، فقد كانت مبرراتهم ان هذا النظام يحمل في طياته جملة من السلبيات منها:

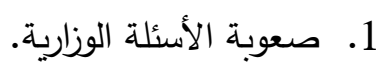

2. الحالة النفسية والتوتر العصبي والنفسي المرافق للامتحانات العامة بشكل يؤثر في إجابة التلميذ أثناء الامتحان الوزاري. 3. للحد من الدروس الخصوصية. 4. تخوف التلميذ في بعض الأمور السلبية التي تحدث في المراكز الامتحانية. 
5. نقل التلميذ إلى مكان غير مدرسته ومدرسيه، يؤدي إلى تذمره.

6. وجود مراقبين في القاعات الامتحانية يصعب التفاهم معهم.

7. المدرسة هي اعرف بمستوى التلاميذ.

8. المبالغ المتربة على إجراء الامتحانات الوزارية والتي يمكن الإفادة منها في بناء المدارس.

9. إعطاء درجة عالية في السعي السنوي يؤدي إلى نجاح التلامذة الأمر الذي يضعف بدوره المستوى العلمي في الدراسة

المتوسطة.

10.تدني نسب النجاح في الصف الأول المتوسط في معظم الددارس يدل على ان نتائج الامتحانات العامة غير حقيقية. 11. مكلفة من حيث ذهاب المعلم إلى المراكز الامتحانية في مناطق أخر بعيدة عن سكنه.

12.الاتفاقات المسبقة والمتبادلة بين بعض الإدارة والمراقبين ومديري المراكز، من اجل ان تحصل كل مدرسة على نسبة نجاح اعلي لتلاميذها عن طريق التساهل أو غض الطرف عن المخالفات للضوابط الامتحانية.

ثالثاً: الجدول (4) يبين إجابات المبحوثين من المشرفين التربويين على نص السؤال هل أنت مع بقاء الامتحانات العامة الوزارية البكلوريا لمرحلة السادس الابتدائي أم لا؟

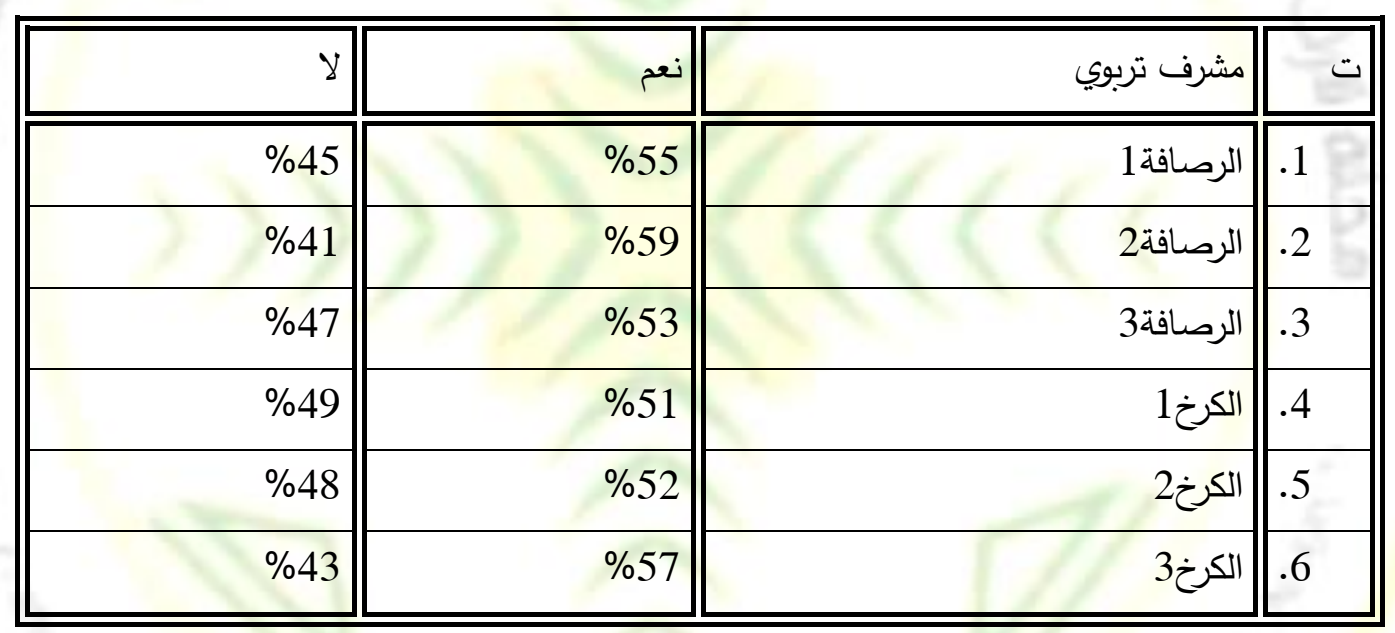

جاءت إجابات المشرفين التربويين بالثكل الآتي:

أعلى نسبة من إجابات للمشرفين التربويين بـ(نعم) في الرصافة/2 وبنسبة 59\% لصالح بقاء النظام الحالي، و نسبة 41\% (لا) يؤيدون النظام الحالي. تليها إجابات المشرفين التربويين في الكرخ/3 وبنسبة إجابات بـ(نعم) بلغت 57\% لصالح بقاء نظام الامتحانات الحالي، يقابلها نسبة الإجابات بـ(لا) 43\% من المشرفين ضد بقاء النظام الحالي.وبعدها الرصافة/1 بنسبة إجابات نعم بلغت 55\%، ونسبة الإجابات بـ (لا) 45\% لبقاء نظام الامتحان الحالي. في حين بلغت إجابات المشرفين التربويين في الرصافة/3 بـ(نعم) لصالح بقاء النظام الحالي 53\%، يقابلها الإجابات بـ(لا) بنسبة 47\% ضد بقاء النظام الحالي للامتحانات، ومن ثم الكرخ/2 بنسبة إجابات نعم لبقاء النظام ألامتحاني الحالي بلغت 52\%، مع نسبة رفض لبقاء النظام الحالي بلغت 
48\%. واخيراً الكرخ/1 بلغت إجابات المشرفين التربويين نعم لبقاء النظام الحالي 51\% مع نسبة إجابات (لا) لبقاء النظام

$$
\text { ألامتحاني الحالي بلغت 49\%. }
$$

وقد كانت مبررات إجابات المشرفين بالثكل الآتي:

أ- المؤيدون بـ(نعم) لبقاء النظام ألامتحاني الحالي فان مبرراتهم كالآتي: 1. من أجل ان يعتاد التلادذة على الامتحانات الوزارية لأنهم سيخوضونها في المراحل الثانوية.

2. التقويم السنوي لإدارات المدارس والمعلمين على أساس نسب النجاح.

3. الامتحانات العامة هي الاختبار الأفضل للمعلمين في تدريس الصف السادس.

4. التعرف على مستوى التلاميذ في المرحلة الابتدائية ولكل معلم ومدرسة على حدة.

5. تعزز رصانة الثهادة العلمية، والتعليم بصورة عامة في البلد.

6. عدم إعطاء الفرصة لإدارات الددارس بالتلاعب بالدرجات.

7. جدية ومثابرة الطالب في الدراسة والقراءة.

8. تحديد مستوى التعليم بأسئلة موحدة لكل تلاميذ الصف السادس بالعراق.

9. لأنها مرحلة مهمة إذ تعد نهاية مرحلة للتلامذة ومقدمة لبداية مرحلة جديدة.

10.بعض المدارس يتأثر تقيمها بالعلاقات الثخصية، والمحسوبية والمنسوبية.

11.يضطر المعلم لإكمال المنهج بشكل أفضل.

12. التقييم بشكل صحيح للمدرسين حيث تقديم الثكر والتثمين لجهودهم.

13.رفد مدارس المتميزين بالتلاميذ الأكفاء وباستحقاق حقيقي.

14.بعض المدارس ترفع معدلات بعض التلاميذ لأسباب عدة منها قبولهم في مدارس الموهوبين والمتميزين.

15. الامتحانات العامة تمثل هيبة التعليم والدولة.

16.منح الشهادة الابتدائية اعتماداً على الامتحانات العامة

17.رفع مستوى التلميذ الدراسي.

18.تهيئة وإعداد تلميذ مثابر وحريص للدراسة المتوسطة.

19.منع استغلال الأهالي لإدارة المدارس.

20. الامتحانات العامة فيها نوع من المصداقية.

ب- - الرافضون لبقاء النظام ألامتحاني الحالي من المشرفين التربوين مبرراتهم كالآتي:

1. وجود ثغرات ونقاط ضعف في كيفية وضع الأسئلة الامتحانية.

$$
\text { 2. عدم الدقة في فحص الدفاتر. }
$$

3. وجود تساهل من قبل المراقبين يسبب الغش 


\section{مجلة لارك لدفلسفة والذلساذيات والعلوم الاجتمهاعية المجلد (3) العدد (42) السذة (2021) بحوث علم الاجتماع}

4. شعور التلميذ بالرهبة والإرباك في الامتحان الوزاري.

5. الامتحانات العامة محدودة الفائدة .

6. . ضياع الوقت والمال والجهد.

7. اختزال نشاط التلميذ بنشاط واحد (الامتحان الوزاري).

8. الدخول الثامل لكافة تلاميذ الصف الساد.

المبحث الرابع:

المحور الثاني:تحليل نتائج السعي والامتحان الوزاري

وبعد الاطلاع على نتائج الامتحانات العامة (البكلوريا) المتمثلة بـ (درجة السعي زائداً درجة الامتحان النهائي الوزاري) للمدارس الابتدائية، اختيرت (60) مدرسة ابتدائية بطريقة عشوائية من بين مدارس محافظة بغداد، بواقع (10) مدارس من كل مديرية

عامة للتربية، كما هي موضحة في الجدول (5).

الجدول (5) السعي السنوي والوزاري للصف السادس الابتدائي للعام الدراسي 2017-2018

\begin{tabular}{|c|c|c|c|c|c|c|c|}
\hline اجتماعيات & علوم & رياضيات & انكليزي & عربي & اسلامية & الدرجة & المديرية \\
\hline 74 & 77 & 70 & 67 & 76 & 78 & السعي السنوي & \multirow{2}{*}{ رصافة 1} \\
\hline 77 & 69 & 74 & 68 & 79 & 81 & الوزاري & \\
\hline 66 & 64 & 64 & 69 & 73 & 75 & السعي السنوي & \multirow[t]{2}{*}{ رصافة2 } \\
\hline 68 & 64 & 52 & 58 & 68 & 79 & الوزاري & \\
\hline 68 & 72 & 65 & 64 & 72 & 74 & ي السنوي & \multirow[t]{2}{*}{ صصافة3 } \\
\hline 64 & 64 & 68 & 56 & 72 & 71 & الوزاري & \\
\hline 78 & 76 & 78 & 76 & 77 & 84 & السعي السنوي & \multirow[t]{2}{*}{ كرخ1 } \\
\hline 72 & 75 & 67 & 71 & 81 & 84 & الوزاري & \\
\hline 70 & 67 & 69 & 67 & 75 & 77 & السعي السنوي & \multirow[t]{2}{*}{ كرخ2 } \\
\hline 76 & 76 & 54 & 68 & 71 & 80 & الوزاري & \\
\hline 73 & 75 & 70 & 75 & 78 & 78 & السعي السنوي & \multirow[t]{2}{*}{ كرخ3 } \\
\hline 71 & 75 & 61 & 58 & 76 & 86 & الوزاري & \\
\hline
\end{tabular}


الجدول (5) يظهر لنا جملة من المعطيات أهمها الآتي:

1. ان متوسطات السعي السنوي لمادة الرياضيات أعلى بكثير من متوسطات الدرجة الوزارية مما يدل على ان المعلمين

$$
\text { يمنحون التلامذة معدلات سعي سنوي أعلى من الاستحقاق لاعتبارات كثيرة ولأسباب عدة. }
$$

2. تنطبق على مادة اللغة الانكليزية الحالة السابقة التي اعتمدت في مادة الرياضيات، علما بأن هاتين المادتين هن من

$$
\text { أكثر المواد الدراسية التي فيها نسب الرسوب عالية. }
$$

3. لا توجد فروق كبيرة ذات بين متوسطات السعي السنوي مقارنة بمتوسطات الدرجة النهائية للامتحانات العامة في باقي

$$
\text { المواد الدراسة (الإسلامية، العربي، العلوم، والاجتماعيات). }
$$

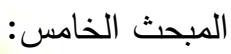

$$
\begin{aligned}
& \text { الاستتتاجات والمقترحات والتوصيات : } \\
& \text { اولاً / الاستتاجات: }
\end{aligned}
$$

1. نسبة إجابات المعلمين ب(نعم) لصالح بقاء النظام الحالي قد بلغت69,6\%، مما يعني ان اغلب المبحوثين من

$$
\text { المعلمين مع بقاء النظام الحالي. }
$$

2. نسبة مديري الددارس الذين أجابوا بـ(نعم) لبقاء نظام الامتحان الحالي كانت 46\% .

3. نسبة المشرفين التربويين المؤيدين لبقاء الامتحانات الوزارية بلغت 54,5\%، ونسبة الرافضين لبقاء الامتحان الوزاري

$$
\text { هي }
$$

4. لاتوجد فروق كبيرة بين متوسطات السعي السنوي بالمقارنة مع متوسطات الدرجة النهائية للادتحانات العامة في أغلب

$$
\text { الدروس عدا مادتي الرياضيات والانكليزي • }
$$

5. تكلف الامتحانات الوزارية مبالغ مالية فضلاً عن الجهد والوقت بالمقارنة مع النتائج التي تسفر عنها. 6. الامتحانات الحالية (الامتحانات العامة، الوزارية، البكلوريا) تحمل في طياتها سلبيات عدة، ولم تتغير أو تتطور بالماهية التي يمكن ان تشكل إضافة للعملية التربوية. 7. الامتحانات المتبعة في الوقت الراهن تثكل عبء نفسي وتربوي على التلامذة واولياء الأمور على حدٍ سواء. 8. الامتحانات الوزارية العامة (البكلوريا) غير محققة لمبدأ العدالة الاجتماعية، لوجود تفاوت مناطقي جغرافي واقتصادي

$$
\text { واجتماعي فيما بين التلامذة . }
$$

$$
\text { ثانياً / التوصيات: }
$$

يمكن تلخيص توصيات الدراسة الحالية برؤية بديل عن النظام ألامتحاني الحالي تتضمن الآتي: 1. جعل الامتحان النهائي للمرحلة الابتدائية امتحاناً مدرسياً بمراقبة و إثراف مدراء المدارس المتوسطة المغذاة من

$$
\text { المدارس الابتدائية وملاكها. }
$$

2. قيام قسم الامتحانات في المديريات العامة للتربية بوضع جدول يتاسب مع امتحانات المرحلة المتوسطة توافقياً. 
3. إن تكون توصيات الدراسة الحالية على سبيل التجربة لعام دراسي واحد وفي مدارس محدودة، وعند نهاية التجربة يُتخذ

القرار المناسب في ضوء النتائج المستخلصة.

ثالثاً/المقترحات:

1. إجراء دراسات عن جدوى الامتحانات الوزارية في مرحلي الدراسة المتوسطة والاعدادية.

2. إجراء دراسات عن البدائل المقترحة للامتحانات العامة البكلوريا.

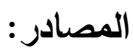

1. العاجز، د. فؤاد علي،(2009)، د. داود درويش حلس، دليل المشرف التربوي، كلية التربية، الجامعة الإسلامية،

غزة.

2. الوقائع العراقية، (2011)، قانون وزارة التربية (22) لسنة 2011 العدد 4209، 19/ 9/ 2011، السنة الثالثة والخمسون.

3. الجنة المشتركة،(1965)، من الوفد الثقافي للجمهورية العربية المتحدة وممثلي التربية والتعليم بالجمهورية العراقية من 1965/4/22-1922 1965، طبع بمطابع إدارة المطبوعات بوزارة التربية والتعليم، القاهرة. 4. الراوي، مسارع،(1966)، مشكلات الرسوب في الثانويات ومصير الخريجين، مطبعة العاني. 5. بول، منرو،(1932) ، تقرير لجنة الكثف والتهذيب، بغداد ، مطبعة الحكومة.

6. وزارة المعارف،(1960)، مقررات وتوصيات المؤتمر الأول للتربية والتعليم، مطبعة وزارة المعارف. 7. جمهورية العراق،(1978)، وزارة التربية، نظام المدارس الابتدائية رقم (30) لسنة 1978، المادة (62). 8. حوري، زهية،(2007)، تقييم المشروعات في البلدان النامية باستخدام طريقة الآثار، رسالة مقدمة لنيل شهادة الدكتوراه الدولة في العلوم الاقتصادية، منشور مقدمة إلى كلية العلوم الاقتصادية وعلوم التسيير، جامعة منتوري،

\section{قسنطينة.}

9. رجب، هناء، (1986)، التعليم في العراق بين الماضي والحاضر، مجلة المعلم الجديد، مجلة تربوية فصلية تصدرها وزارة التربية، الجزء الثالث، المجلد الثالث والأربعون، تشرين الأول.

10.زردق، د. احمد عبدالرحيم، بسيوني، د. محمد سعيد، (2011)، مبادئ دراسات الجدوى الاقتصادية، كود رقم/ 123، برنامج محاسبة البنوك والبورصات.

11.نظام الامتحانات العامة رقم (19) لسنة 1972، استتادا إلى حكام الفقرة ( آ ) من مادة 6 والخمسين من الدستور المؤقت ومادة 12 من قانون وزارة التربية رقم ( 124) لسنة 1971.

12.وزارة التربية، (2018-2019)، المديرية العامة للتخطيط التربوي، قسم الإحصاء، بيانات عام، جدول (2- 21). 13.متولى، مصطفى،(1983)،الإشراف الفني في التعليم دراسات مقارنة، الإسكندرية المطبوعات. 
Sources:

1. The Impotent, Dr. Fouad Ali, (2009), Dr. Dawood Darwish Hillis, Educational Supervisor's Guide, College of Education, Islamic University, Gaza.

2. The Iraqi facts, (2011), Law of the Ministry of Education (22) of 2011, No. 4209, 9/19/2011, the fifty-third year.

3. Jumli, the delegation, the culture of the United Arab Republic and the representatives of education in the Iraqi Republic from 4/22/1965 to 22/5/1965, printing presses, printing publications at the Ministry of Education, Cairo.

4. Al-Rawi, Musa'a, (1966), Problems of Failure in High Schools and the Fate of Graduates, AlAni Press.

5. Paul, Monroe, (1932) Report of the Commission for Disclosure and Discipline, Baghdad, Government Press.

6. The Ministry of Education, (1960), Decisions and recommendations of the First Conference on Education, Ministry of Education Press.

7. Republic of Iraq, (1978), Ministry of Education, Primary School System No. (30) for the year 1978, Article (62).

8. Houry, Zahia, (2007), Evaluation of Projects in Developing Countries Using the Archeology Method, Thesis Submitted to Obtaining a State Doctorate in Economic Sciences, a publication submitted to the Faculty of Economic Sciences and Management Sciences, University of Mentouri, Constantine.

9. Rajab, Hana, (1986), Education in Iraq between Past and Present, The New Teacher Magazine, a quarterly educational magazine issued by the Ministry of Education, Part Three, Volume Forty-Three, October.

10. Zoroq, Dr. Ahmed Abdel Rahim, Bassiouni, d. Muhammad Saeed, (2011), Principles of Economic Feasibility Studies, Code No. / 123, Banking and Stock Exchange Accounting Program. 
11. System of public examinations No. (19) for the year 1972, based on the provisions of Paragraph (A) of Article 56 of the Interim Constitution and Article 12 of the Ministry of Education Law No. (124) of 1971.

12. Ministry of Education, (2018-2019), General Directorate of Educational Planning, Department of Statistics, General Data, Table (2-21).

13. Metwally, Mustafa, (1983), Technical Supervision in Education, Comparative Studies, Alexandria Publications. 